\title{
Evaluation of Initial Drug Selection For Newly Medicated Hypertensives at the Westinghouse Electric Corporation
}

\author{
Chris M. Kozma, Robert D. Pannone, Gene Clayton and Edwin C. Hedblom
}

\begin{abstract}
OBJECTIVE: To describe prescribing practices and costs of antihypertensive medications in a large employee health program one to three years after the issuance of the recommendations of the Joint National Committee on Detection, Evaluation, and Treatment of High Blood Pressure (JNC) for initial treatment of uncomplicated hypertension with beta blockers and diuretics as monotherapy, based on ample evidence that these agents reduce morbidity and mortality.
\end{abstract}

SETTING: Employee health plan for Westinghouse Electric Corp.

PATIENTS: 1,218 newly diagnosed hypertensives

DESIGN: To evaluate initial pharmacotherapy for newly medicated hypertensives and adherence to the JNC- $V$ recommendations, paid medical/pharmacy claims from Westinghouse Electric Corporation's employee health plan for 1994-96 were analyzed. This analysis was modeled after a similar study of John Deere employees in which the majority received monotherapy with calcium channel blockers or ACE inhibitors.

MAIN OUTCOME MEASURES: Antihypertensive medication usage profiles were generated to determine prescription patterns and utilization. Prescription expenditures were evaluated to assess the economic impact of prescribing decisions.
RESULTS: Of 16,523 employees with hypertension, 1,218 were newly treated with pharmacotherapy. The initially prescribed agents for these newly medicated hypertensives were: beta blockers $20 \%$, diuretics $19 \%$, calcium channel blockers $23 \%$, ACE inhibitors $23 \%$, and others $15 \%$. Medication with ACE inhibitors and calcium channel blockers was four to five times more costly than treatment with diuretics and beta blockers.

CONCLUSION: By 1996, prescribing patterns for newly medicated hypertensive patients had not changed significantly since the JNC-V recommendations. Physician prescribing habits continue to show that the primary drugs recommended for initial treatment of hypertension are used only $39 \%$ of the time. Health plans may have the opportunity to influence care in a clinically appropriate manner with medications that have lower costs by focusing on beta blockers and diuretics for first-line treatment of uncomplicated hypertension.

KEYWORDS: Hypertension, Antihypertensive medications, JNC-V recommendations

J Managed Care Pharm 1999: 505-509

\section{$\Delta$}

AUTHORS

CHRIS M. KOZMA, R.PH., P.HD., is Research Director, Strategic Outcomes Services, Research Triangle Park, NC, and Professor, University of South Carolina, Columbia, SC; ROBERT D. PANNONE, B.S., PHARM.D., Reeder, Kozma $\&$ Associates, Columbia, SC; GENE CLAYTON is President, Clayton and Associates, Allison Park, $\mathrm{Pa}$ and was formerly Vice President of Benefits, Westinghouse Electric Corporation; EDWIN C. HEDBLOM, PHARM.D., Astra Pharmaceuticals L.P., Wayne, Pa

AUTHOR CORRESPONDENCE: Chris M. Kozma, R.Ph., Ph.D., Department of Pharmacy Practice, University of South Carolina, Columbia, SC 29208; phone. 803-777-7815; fax: 803-777-2820; e-mail: kozma@pharm.sc.edu

ACKNOWLEDGEMENT: This work was supported by a grant from Astra USA, Inc Copyright $\odot 1999$ Academy of Managed Care Pharmacy, Inc. All rights reserved.
$\mathrm{H}$ igh blood pressure is a primary risk factor for congestive heart failure, stroke, acute myocardial infarction (AMI), peripheral vascular disease, and chronic renal failure. ${ }^{1}$ Every day in the United States, 2,600 people die from these and other manifestations of cardiovascular disease. ${ }^{2}$ Although increased awareness of the symptoms and risks of high blood pressure has resulted in substantial decreases in hypertension-related death and disability since the 1960 s, hypertension still remains a major health problem. ${ }^{1}$ In 1995 , 50 million Americans had diagnosed hypertension, and as many as two million newly diagnosed hypertensive patients will require therapy each year. ${ }^{3}$

Pharmacotherapy is a mainstay of hypertension management and has been shown to reduce the incidence of cardiovascular morbidity and mortality, primarily as a result of reductions in stroke and coronary heart disease (CHD). ${ }^{4-7}$ Due to the prevalence of hypertension and the high costs of therapy, first-line prescribing decisions affect large numbers of patients and have significant economic implications.

\section{BETA BLOCKERS, DIURETICS VS NEWER AGENTS}

In 1993 the Fifth Joint National Committee on the Detection, Evaluation, and Treatment of High Blood Pressure (JNC-V) 
recommended monotherapy with either hydrochlorothiazide or beta blockers for initial treatment of uncomplicated hypertension. ${ }^{6}$ Those recommendations were reinforced in the JNC-VI guidelines issued in November 1997, with the added provision that low-dose combinations of diuretics with other antihypertensives are also acceptable. ${ }^{8}$ Although these recommendations have been challenged by advocates of newer antihypertensive agents such as calcium channel blockers, alpha blockers, ACE inhibitors, and angiotensin receptor blockers, diuretics and beta blockers remain the only classes of drugs that have been widely documented to reduce morbidity and mortality from hypertension-associated cardiovascular disease. . $, 8,9$

Two large metaanalyses have established the efficacy of beta blockers and diuretics and the long-term morbidity and mortality outcomes associated with their use. Collins et al. performed a metaanalysis of 37,000 individuals in 14 randomized clinical controlled trials in which the chief agents used were beta blockers and diuretics. ${ }^{4}$ Mean diastolic blood pressure (DBP) was reduced by $5 \mathrm{~mm} \mathrm{Hg}$ to $6 \mathrm{~mm} \mathrm{Hg}$ and clinical outcomes were significantly improved with a $42 \%$ reduction in stroke, a $14 \%$ reduction in CHD, and a $21 \%$ reduction in vascular mortality. ${ }^{4}$

Psaty et al. conducted a metaanalysis of 18 clinical studies to evaluate the outcomes of first-line antihypertensive therapies in reducing and preventing major cardiovascular events and mortality. Clinical evidence resulting from this study supported the JNC-V recommendations and led the authors to conclude that until results of long-term clinical trials evaluating the newer agents are known, diuretics and beta blockers should remain routine first-line therapy for hypertension. ${ }^{10}$

Regardless of the JNC-V recommendations and cumulative clinical evidence, use of beta blockers and diuretics has declined dramatically. ${ }^{9.11-15}$ Calcium channel blockers and ACE inhibitors are commonly prescribed as initial agents, cost up to 30 times more than beta blockers and diuretics, and place a significant cost burden on health care payors and patients. Yet the magnitude of these drugs' effects on morbidity and/or mortality from cardiovascular causes has not been fully documented. ${ }^{6,8,9}$

In 1994, the Westinghouse Electric Corporation of Pittsburgh, PA, began analyzing paid claims data from its self-funded corporate health benefit program for its members nationwide to ascertain appropriateness of first-line antihypertensive medications prescribed for patients who were newly receiving pharmacotherapy to manage their hypertension. The researchers also evaluated medication-taking behavior, high-cost hypertensive patients, and use of beta blockers after myocardial infarction. This paper describes the claims analysis and characterizes firstline prescribing practices of physicians at Westinghouse in the aftermath of the JNC-V recommendations.

\section{JOHN DEERE STUDY}

The present analysis of Westinghouse paid claims was modeled after a similar study of John Deere employee claims that assessed the initial selection of antihypertensive medications, treatment patterns, and the presence of coexisting medical conditions among newly diagnosed hypertensive patients. Jerome et al., ${ }^{12}$ retrospectively analyzed paid claims for the period from January 1991 through December 1992 at Deere \& Company, located in the Waterloo and Quad Cities areas of Iowa. Some $55 \%$ of John Deere patients were initially treated with monotherapy; the majority received either a calcium channel blocker or an ACE inhibitor. This finding is not surprising in view of the JNC-IV (1988) position that initial therapy could be chosen with equal confidence from among diuretics, beta blockers, calcium channel blockers, or ACE inhibitors. ${ }^{16}$

Researchers at John Deere concluded that beta blockers and diuretics should be reemphasized as the primary medications for hypertension, because these agents are supported by the JNC and are effective at lowering morbidity, mortality, and health care costs.

\section{METHODS}

Pharmacy and medical claims paid from July 1, 1994, through June 30, 1996, were examined, as well as eligibility data from the Westinghouse Electric Corporation's health benefit program. To be included in the study, Westinghouse employees had to be continuously enrolled for the two-year duration of the study, have at least two medical claims for hypertension or hypertension-related conditions as a primary or secondary diagnosis, or have at least three claims for an antihypertensive medication. Hypertension diagnoses were defined by the Ninth International Classification of Diseases (ICD-9-CM) codes and antihypertensive medications were defined by generic drug class. ${ }^{17}$

A subgroup of employees newly receiving antihypertensive medication was identified from those employees diagnosed with hypertension. Employees were included if they 1) were enrolled from July 1, 1994, through June 30, 1996, but received no antihypertensive medication during the first six months, and 2) received at least one prescription for an antihypertensive medication dispensed between December 31, 1994, and June 30, 1996. Employees were excluded if they did not actively receive medication for a period of four months or more between December 31, 1994, and June 30, 1996, or if they were prescribed a new class of antihypertensive medication in the last month of the study, and/or the renewal date for the previous medication was not reached within the study period.

For each eligible employee an antihypertension medication usage profile was generated that included dispensing dates, days supply, and class of initial medication: diuretic (loop, potassium sparing, and thiazide related); beta blocker; calcium channel blocker; ACE inhibitor; and other. Newly medicated hypertensives were further categorized according to whether they received monotherapy, sequential monotherapy, stepped care, and two or more drugs. Definitions of these categories are provided in Table 1

All employees prescribed a beta blocker or calcium channel blocker were investigated for a concurrent diagnosis of ischemic heart disease (ICD-9-CM codes 410-414), and employees 
prescribed an ACE inhibitor were evaluated for a concurrent diagnosis of congestive heart failure (ICD-9-CM code 428) Independent confirmation of diagnosis was not conducted.

Average and total prescription expenditures were evaluated for all hypertensive employees.

\section{RESULTS}

Claims were evaluated for 121,563 employees, beneficiaries, and retirees. These employees were evenly divided according to sex ( $52 \%$ females, $48 \%$ males) and averaged $38 \pm 20.2$ years of age. Of these, 16,523 employees were identified by medical and drug claims as having hypertension. This subgroup had an average age of $56 \pm 10.0$ years and a higher representation of males (55\%).

Among employees meeting the study inclusion criteria for hypertension, a total of 1,428 (8.6\%) had been newly prescribed an antihypertensive agent during the period from December 31, 1994, through June 30, 1996. Of these, 210 employees were excluded because they did not actively receive medication for at least four months. Therefore, 1,218 employees with newly prescribed antihypertensive medication were included in the analysis.

Assignment to the Westinghouse category of "initial hypertensive" required absence of a diagnosis code or prescription for the first six months of the study period, and at least one prescription thereafter. Some patients in this category were lost to analysis because they did not receive medication for a period of four months or longer, and could not be accurately classified in a therapy group. Similarly lost were patients who received a different class of drug late in the study interval, because it was not possible to distinguish whether the employee received stepped care or sequential monotherapy.

Of those newly medicated for hypertension, 780 employees (64\%) received monotherapy; 213 (18\%) received sequential therapy, $135(11 \%)$ received stepped therapy and $90(7 \%)$ received two or more drugs.

In all treatment groups except those who received multiple drugs ( $n=1128$ ), beta blockers comprised $20 \%$ of first-line prescriptions ( $\mathrm{n}=228)$, diuretics $19 \%(\mathrm{n}=216)$, calcium channel blockers $23 \%(n=254)$, ACE inhibitors $23 \%(n=260)$, and other drugs $15 \%(n=170)$. In the group receiving monotherapy, approximately $14 \%(20 / 148)$ of those who received calcium channel blockers also had a paid claim for ischemic heart disease. Of those treated with a beta blocker, approximately $16 \%$ (27/164) had a paid claim for ischemic heart disease, and $1 \%$ (2/181) of employees started on an ACE inhibitor had a paid claim for congestive heart failure.

Prescription expenditures were examined for all hypertensive subjects who met the initial study inclusion criteria $(n=16,523)$. ACE inhibitors and calcium channel blockers were the most costly medications prescribed. Combined total expenditures (not including rebates or patient contributions) for ACE inhibitors and calcium channel blockers were $\$ 4.3$ million dollars compared to approximately $\$ 1$ million dollars for beta blockers

\begin{tabular}{l|l}
\hline Table 1. Employee Profile Categories \\
\hline Therapy Type & Definition \\
\hline Monotherapy & $\begin{array}{l}\text { Patients prescribed a single pharmacologic } \\
\text { class of antihypertensive medication during } \\
\text { the inclusion period }\end{array}$ \\
\hline Stepped care & $\begin{array}{l}\text { Patients who were prescribed a drug from a } \\
\text { single pharmacologic class but had agents } \\
\text { from one or more other classes added to } \\
\text { their regimen at least seven days after initial } \\
\text { therapy }\end{array}$ \\
\hline $\begin{array}{l}\text { Dual therapy } \\
\text { (2+ Drugs) }\end{array}$ & $\begin{array}{l}\text { Patients who were prescribed a drug from a } \\
\text { single pharmacologic class but had agents } \\
\text { from one or more other classes added to } \\
\text { their regimen within five days after initial } \\
\text { therapy }\end{array}$ \\
\hline $\begin{array}{l}\text { Sequential } \\
\text { monotherapy }\end{array}$ & $\begin{array}{l}\text { Patients who were prescribed two or more } \\
\text { drugs from separate pharmacologic classes } \\
\text { but never concurrently }\end{array}$ \\
\hline
\end{tabular}

and diuretics. Average prescription expenditures for ACE inhibitors and calcium channel blockers were four to five times higher than those for diuretics and beta blockers

\section{DISCUSSION}

The findings in this analysis are consistent with national trends of underutilization of beta blockers and diuretics. ${ }^{9.11,12,15}$ Although $64 \%$ of employees were treated with monotherapy at Westinghouse, calcium channel blockers and ACE inhibitors represented $42 \%$ of all prescriptions for monotherapy (see Table 2). Analyzed across all types of therapy, calcium channel blockers and ACE inhibitors accounted for $46 \%$ of all initial prescriptions, while beta blockers and diuretics made up only $39 \%$. Use of ACE inhibitors and calcium channel blockers as initial therapy was not associated with ICD-9 codes of ischemic heart disease or congestive heart failure.

Underutilization of beta blockers and diuretics may be attributable to widely held perceptions that they have more

Table 2. Total and Average Expenditure by Drug Class For Hypertensive Patients in the Westinghouse Population $(\mathrm{N}=16,523)$

\begin{tabular}{l|c|c}
\hline Drug Class & Total Expenditures & $\begin{array}{l}\text { Average Expenditures } \\
\text { (Cost per claim) }\end{array}$ \\
\hline Diuretics & $\$ 347,756$ & $\$ 6.10$ \\
\hline Beta blockers & $\$ 654,447$ & $\$ 10.76$ \\
\hline $\begin{array}{l}\text { Calcium channel } \\
\text { blocker }\end{array}$ & $\$ 2,106,692$ & $\$ 30.87$ \\
\hline $\begin{array}{l}\text { Antihypertensives } \\
\text { includes ACE } \\
\text { inhibitors }\end{array}$ & $\$ 2,201,607$ & $\$ 23.03$ \\
\hline
\end{tabular}


Table 3. Comparison of Westinghouse vs. John Deere Findings

\begin{tabular}{|c|c|}
\hline \multicolumn{2}{|c|}{ Comparisons of Health Care Populations } \\
\hline $\begin{array}{l}\text { Westinghouse } \\
1994-1996 \text { data } \\
64 \% \text { monotherapy } \\
18 \% \text { sequential monotherapy } \\
11 \% \text { stepped therapy } \\
7 \% 2+\text { drug }\end{array}$ & $\begin{array}{l}\text { John Deere } \\
1991-1992 \text { data } \\
55 \% \text { monotherapy } \\
18 \% \text { sequential monotherapy } \\
22 \% \text { stepped therapy } \\
5 \% 2+\text { drugs }\end{array}$ \\
\hline \multicolumn{2}{|c|}{ Breakdown of Prescribing for Monotherapy } \\
\hline $\begin{array}{l}\text { Westinghouse } \\
18 \% \text { Diuretic } \\
21 \% \text { Beta blocker } \\
19 \% \text { Calcium channel blockers } \\
23 \% \text { ACE inhibitor } \\
19 \% \text { Other }\end{array}$ & $\begin{array}{l}\text { John Deere } \\
22 \% \text { Diuretic } \\
14 \% \text { Beta blocker } \\
30 \% \text { Calcium channel blockers } \\
22 \% \text { ACE inhibitor } \\
12 \% \text { Other }\end{array}$ \\
\hline
\end{tabular}

side effects and are less easily tolerated than other medications. Evidence from large clinical trials, however, shows that most patients tolerate both beta blockers and diuretics, and rates of side effects for these drugs are not significantly different from those of newer agents. ${ }^{9}$ The VA cooperative trials and the TOHMS trial documented favorable side-effect profiles for beta blockers and diuretics, while SHEP, MRC, and STOP trials indicate these products lower the risk of stroke and coronary events. ${ }^{18-23}$ Moreover, appropriate product selection from the variety of beta blockers currently available can minimize side effects. Today's range of products allows selection of a beta blocker with cardioselectivity, intrinsic sympathomimetic activity, pharmacokinetics (dosing, lipophilicity), and pharmacodynamic properties appropriate to an individual patient's specific medical profile. ${ }^{24}$

This analysis of Westinghouse claims data adds to the growing evidence that the JNC-V guidelines are not consistently followed. Siegel and Lopez examined the influence of the JNC-V recommendations by surveying antihypertensive prescriptions dispensed between 1992 and 1995 by 35,000 national retail pharmacies. ${ }^{15}$ Finding a clear decline in the use of beta blockers and diuretics and increased use of ACE inhibitors and calcium channel blockers, they concluded that the JNC-V recommendations had little effect on prescribing patterns. Commentary on the Siegel report suggested several reasons for the decline in beta blocker and diuretic use, including perceived superiority of newer medications, marketing efforts of the pharmaceutical industry, and the relatively low impact of national guidelines. ${ }^{25}$

Hypertension is a chronic condition requiring persistent, long-term treatment that carries a substantial cost for both insurers and patients. The choice of initial pharmacotherapy is important in controlling these costs. In our claims analysis, total expenditures reflect the pharmaceutical budgetary impact on Westinghouse. Expenditures for calcium channel blockers and ACE inhibitors were several times greater than those for beta blockers and diuretics (see Table 2). On a global level, 1996 prescription expenditures of health maintenance organi- zations (HMOs) were much higher for the newer classes of antihypertensives, totaling $\$ 341.5$ million for ACE inhibitors, $\$ 471$ million for calcium channel blockers, and \$157.6 million for beta blockers. ${ }^{26}$ Per member per year HMO expenditures were $\$ 3.05, \$ 6.06$, and $\$ 9.11$ for beta blockers, ACE inhibitors and calcium channel blockers, respectively.

Formularies were originally developed to promote appropriate prescribing and to control costs. Yet rebates and incentive programs can influence which drugs attain formulary status and which drugs are prescribed. Several calcium channel blockers and virtually all ACE inhibitors are branded, while the majority of diuretics and beta blockers have generic equivalents with no available rebates or incentives

In the setting of employer health programs, the Westinghouse data validate and confirm the prescribing trends observed by John Deere researchers (see Table 3), and lead to the same conclusion: That beta blockers and diuretics offer an opportunity to improve the quality of care at reduced costs. Frequently, programmatic savings are only achieved when costs are considered across departmental budgets. For example, greater expenditures for prescriptions charged to formulary budgets are often required to reduce costs of outpatient care. The Westinghouse data show that increased use of beta blockers and diuretics can lower prescription costs and realize savings within compartmentalized budgets. Appropriate prescribing of beta blockers̈ and diuretics can translate into long-term clinical and economic benefits'across the system of care.

Although the Westinghouse analysis was similar in design to the John Deere study, differences in inclusion and exclusion criteria may exist that have yielded somewhat different study populations. John Deere researchers defined a hypertensive individual by a single primary or secondary ICD-9-CM code indicating a diagnosis of hypertension during the two-year study, whereas Westinghouse required two or more diagnoses or three or more antihypertensive prescriptions. The Westinghouse approach would include fewer false positives - that is, fewer patients with transient hypertension. Such differences, if real, would skew the prevalence of hypertension in the Westinghouse population and the decision whether to medicate, but would not be expected to affect the choice of initial antihypertensive agent once medication is chosen as the appropriate management strategy.

This study, which included all subjects who retained continuous eligibility in the Westinghouse health program, is less likely to have selection bias favoring compliant medication users. In contrast, the John Deere inclusion requirement of a paid drug claim near the end of the study may have eliminated noncompliant patients. Without information on whether noncompliance was attributable to the economic burden of medication purchase on patients, or to untenable side effects, this study cannot reliably conclude whether the observed prescribing trends are biased by this sampling difference. The similarity of prescribing behavior seen in the two studies suggests they are not.

This evaluation permits characterization of prescribing behavior in an employee health program setting. It is subject to 
the limitations of any retrospective claims-based analysis. Data acquisition is constrained by access to and information contained in a preexisting, controlled-parameter database.

This Westinghouse claims data, collected two to four years ago, reflect prescribing patterns following JNC-V guidelines that have been superseded by JNC-VI. ${ }^{8}$

Because the newer guidelines are relatively unchanged regarding first-line use of diuretics and beta blockers for treatment of uncomplicated hypertension, these results still bear on the economic impact of nonadherence to JNC's recommendations.

Costs to individuals with hypertension are also noteworthy. Specific economic analysis was not conducted for the subgroup of Westinghouse patients who were newly medicated for hypertension. However, average expenditures allow projection of the economic impact on the patient who pays a percentage of the cost every time a prescription is dispensed. High cost of medication may be a barrier to hypertension care for some patients and may deter proper adherence to their regimen of therapy. ${ }^{27}$

\section{CONCLUSIONS}

This research suggests that prescribing patterns for initial pharmacotherapy of hypertension have not changed significantly since the issuance of JNC-V recommendations. In light of updated JNC recommendations and consistent with economic impact data, beta blockers and diuretics merit wider use as first-line agents to treat uncomplicated hypertension. Reemphasis on the appropriate use of beta blockers and diuretics offers health plan administrators and physicians an opportunity to influence care in a manner that is clinically appropriate and in concordance with national standards for managing hypertension, with medications that have lower acquisition costs.

Careful consideration of diuretics and beta blockers should guide managed care organizations' formulary decisions and treatment recommendations. In implementing those decisions, managed care organizations should clearly communicate to prescribers the role of beta blockers and diuretics in the treatment of uncomplicated hypertension. Finally, the evidencebased JNC-VI recommendations provide a strong basis for decision making, and the data from this study at Westinghouse show that policies that support the most appropriate use of antihypertensive medications are also cost-effective.

\section{References}

1. Burt V, Cutler J, Higgins M, et al. Trends in the prevalence, awareness, treatment and control of hypertension in adult US population. Data from the health examination surveys, 1960 to 1991. Hypertension. 1995; 26: 60-69. 2. American Heart Association Statistics, 1997 Heart and Stroke Statistical Update, Dallas, Texas. http://www.americanheart.org/Scientific/HSstats97/ index.html (accessed 3/17/98).

3. Cook NR, Cohen J, Hebert PR, et al. Implications of small reductions in diastolic blood pressure for primary prevention. Arch Intern Med 1995; 155: 701-09 4. Collins R, Peto R, MacMahon S, et al. Blood pressure, stroke, and coronary heart disease: Part 2, short-term reductions in blood pressure: overview of randomized drug trials in their epidemiological context. Lancet 1990; 335: 827-38. 5. MacMahon S, Peto R, Cutler J, et al. Blood pressure, stroke, and coronary heart disease, Part 1: prolonged differences in blood pressure: prospective observational studies corrected for the regression dilution bias. Lancet 1990; 335: $765-74$

6. Joint National Committee on Detection, Evaluation, and Treatment of High Blood Pressure. The fifth report of the Joint National Commiltee on Detection, Evaluation, and Treatment of High Blood Pressure (JNC-V). Arch Intern Med 1993; 153: 154-83.

7. National Center for Health Statistics, Health United States, 1996-1997, and Injury Chartbook, Hyattsville, Md: National Center for Health Statistics;1997. 8. The sixth report of the Joint National Committee on Prevention, Detection, Evaluation, and Treatment of High Blood Pressure (JNC-VI). National Institutes of Health, National Heart, Lung, and Blood Institute; 1997 Nov. NIH publication No. 98-4080.

9. Alderman M. Which antihypertensive drugs first—and why! JAMA 1992; 267: 2786-87.

10. Psaty BM, Smith NL, Siscovick DS, et al. Health outcomes associated with antihypertensive therapies used as first-line agents. A systematic review and meta-analysis. JAMA 1997; 227: 739-45.

11. Goldstein S. B-blockers in hypertensive and coronary heart disease. Arch Intern Med 1996; 156: 1267-76.

12. Jerome M, Xakellis GC, Angstman G, Patchin W. Initial medication selection for treatment of hypertension in an open-panel HMO.J Am Board Fam Pract 1995; 8: 1-6.

13. Knapp DA, Michocki RJ, Richardson JP, Knapp DA. An evaluation of antihypertensive prescribing practices. PharmacoEconomics 1994; 5: 408-18. 14. Kaplan M, Gifford R. Choice of initial therapy for hypertension. JAMA 1996; 275: 1577-80.

15. Siegel D, Lopez J. Trends in antihypertensive drug use in the United States. Do the JNC-V recommendations affect prescribing? JAMA 1997; 278: 1745-48. 16. Joint National Committee on Detection, Evaluation, and Treatment of High Blood Pressure. The fourth report of the Joint National Committee on Detection, Evaluation, and Treatment of High Blood Pressure (JNC-IV). Arch Intern Med 1988; 148: 1023-38.

17. International Classification of Diseases, 9 th revision, Clinical Modification Baltimore: HCIA, 1993.

18. Veterans Administration Cooperative Study Group on Antihypertensive Agents. Effects of treatment on morbidity in hypertension: results in patients with diastolic blood pressures averaging 115 through $129 \mathrm{~mm} \mathrm{Hg}$. JAMA 1967; 202: 116-22.

19. Veterans Administration Cooperative Study Group on Antihypertensive Agents. Effects of treatment, Il: results in patients with diastolic blood pressures averaging 90 through $114 \mathrm{~mm} \mathrm{Hg.} \mathrm{JAMA} \mathrm{1970;} \mathrm{213:} \mathrm{1143-52.}$ 20. Neaton JD, Grimm RH Jr, Prineas RJ, et al. for the Treatment of Mild Hypertension Research Group. Treatment of Mild Hypertension Study (TOHMS): final results. JAMA 1993; 270: 713-24

21. SHEP Cooperative Research Group. Prevention of stroke by antihypertensive drug treatment in older persons with isolated systolic hypertension: final results of the Systolic Hypertension in the Elderly Program (SHEP). JAMA 1991; 265: 3255-64.

22. MRC Working Party. Medical research council trial of hypertension in older adults: principal results. BMJ 1992; 304: 405-12.

23. Dahlö B, Lindholm LH, Hansson L, et al. Morbidity and mortality in the Swedish Trial in Old Patients with Hypertension (STOP-Hypertension). Lancet 1991; 338: 1281-85.

24. Yedinak KC. Formulary considerations in selection of B-blockers. Pharmaco Economics 1993; 4: 104-21.

25. Lenfant $C$. JNC Guidelines. Is the message getting through? JAMA.

December 1997; 278: 1778-79.

26. CibaGeneva Pharmacy Benefit Report. Facts and Figures. 1996 Edition. CibaGeneva Pharmaceuticals. 556 Morris Avenue, Summit NJ 07901

27. Flack JM, Novikov SV, Ferrario CM. Benefits of adherence to anti-hypertensive drug therapy. Eur Heart J 1996;17(suppl A):16-20. 